\title{
A new decision making model for diagnosing acute appendicitis among non-pregnant women and its comparison with alvarado scoring system
}

\author{
Maliheh Arab $^{1} * \mathbb{D}$, Behzad Nemati Honar ${ }^{2}$, Behnaz Ghavami ${ }^{3}$, Robabeh Ghodssi-Ghassemabadi ${ }^{4}$, Mahsa Aghaei ${ }^{5}$, \\ Nasrin Yousefi ${ }^{6}$, Kourosh Sheibani ${ }^{7}$
}

Received: 8 Jul 2020

Published: $21 \mathrm{Jul} 2021$

\section{Abstract}

Background: Although acute appendicitis is a common problem, it remains a difficult diagnosis to establish, particularly among females of reproductive age. The present study was conducted to devise a new decision making model for diagnosing acute appendicitis in non-pregnant women.

Methods: The present study was a retrospective study consisting of women who had undergone an appendectomy between 2007 and 2015 at the emergency department of Imam Hossein Medical Center, Tehran, Iran. The inclusion criteria were being a female, presenting with abdominal pain, being a suspected case of acute appendicitis, and undergoing an emergency appendectomy. A classification and regression tree (CART) analysis was performed to partition exam and laboratory data obtained from these patients into homogeneous groups in order to develop a prediction rule for appendicitis diagnosis.

Results: The study population included 433 non pregnant women who underwent emergency operations with a preliminary diagnosis of acute appendicis. Out of these patients, 295 patients $(68.1 \%)$ were appendicitis positive based on the pathology exam results, while 138 patients had a normal appendix, indicating a negative appendectomy rate of $31.8 \%$. The final devised CART model included hemoglobin level, PMN count, age, and history of abdominal incision and yielded a sensitivity of $82.7 \%$ and specificity of $55.8 \%$, which were better than Alvarado prediction results for the Asian population.

Conclusion: We have devised a simple and cost effective prediction model for predicting the outcome among non-pregnant women undergoing emergency appendectomy operation with good sensitivity and specificity compared to the Alvarado model.

Keywords: Appendicitis, Prognosis, Decision Making, Model

Conflicts of Interest: None declared

Funding: None

*This work has been published under CC BY-NC-SA 1.0 license.

Copyright $₫$ Iran University of Medical Sciences

Cite this article as: Arab M, Nemati Honar B, Ghavami B, Ghodssi-Ghassemabadi R, Aghaei M, Yousefi N, Sheibani K. A new decision making model for diagnosing acute appendicitis among non-pregnant women and its comparison with alvarado scoring system. Med J Islam Repub Iran. 2021 (21 Jul);35:93. https://doi.org/10.47176/mjiri.35.93

\section{Introduction}

Acute appendicitis is the most common indication for emergency surgery worldwide, with an incidence of 1.17 per 1000 and lifetime risk of $8.6 \%$ in men and $6.7 \%$ in

\footnotetext{
Corresponding author:Dr Maliheh Arab, drmarab@sbmu.ac.ir

1. Department of Gyneco-Oncology, Shahid Beheshti University of Medical Sciences, Tehran, Iran

2. Department of Surgery, Shahid Beheshti University of Medical Sciences, Tehran, Iran

3. Department of Laparoscopy, Tehran University of Medical Sciences, Tehran, Iran

4. Department of Biostatistics, Faculty of Medical Sciences, Tarbiat Modares University, Tehran, Iran

5. Shahid Beheshti University of Medical Sciences, Tehran, Iran

${ }^{6 .}$ Scince and Research Branch, Islamic Azad University, Tehran, Iran

7. Basir Eye Health Research Center, Tehran, Iran
}

women (1-4). Although acute appendicitis is a common problem, it remains a difficult diagnosis to establish particularly among females of reproductive age. Since

\section{$\uparrow$ What is "already known" in this topic:}

Although acute appendicitis is a common problem, it remains a difficult diagnosis to establish, particularly among females of reproductive age. To help its diagnosis, some clinical scores have been formulated based on signs and symptoms, physical exam and laboratory findings, as well as patient characteristics, in order to help reaching a diagnosis.

\section{$\rightarrow$ What this article adds:}

In the present study, we have devised a simple and cost effective prediction model for predicting the outcome among non-pregnant women undergoing emergency appendectomy operation with good sensitivity and specificity. 
other genitourinary and gynecological inflammatory conditions such as ectopic pregnancy and ovarian cyst complications often overlap with symptoms of appendicitis, a decision to operate, observe or further work-up a patient is often unclear $(5,6)$. The traditional gold standard for preventing appendicular perforation is early surgical intervention, but the high rate of unnecessary negative appendectomies (15 to $30 \%$ ), leads to unnecessary morbidity and even mortality (7-10). In recent years the use of computed tomography (CT) has reduced the number of negative appendectomies and specially benefits women 45 years of age and younger; but the process of imaging might cause a delay in appendectomy and elevates the risk of perforation, which is considerable especially in younger patients $(7,11-15)$.

Some clinical scores have been formulated based on signs and symptoms, physical exam and laboratory findings, as well as patient characteristics, in order to help reaching a diagnosis (16-26). An ideal scoring system would work as a tool that speeds up and increases the accuracy of decision-making and at the same time reduces the need for potentially harmful and expensive procedures (23). The Alvarado score introduced in 1986, and modified in 1994 has been a widely used scoring system due to its accessibility and low cost (24). But the utility of clinical scoring in the diagnosis of appendicitis remains controversial and the accuracy of Alvarado scoring in the Asian population has been disappointingly low $(27,28)$. On the other hand, several parameters, such as age, gender and duration of symptoms prior to presentation, that affect the sensitivity and specificity of diagnosing score are absent in the Alvarado scoring system (26).

The goal of the present study was to introduce a new decision making model for diagnosing acute appendicitis in non-pregnant women, based on clinical and para clinical findings.

\section{Methods}

This was a retrospective study consisting of 433 women who had undergone an appendectomy between 2007 and 2015, at the emergency department of Imam Hossein Medical Center, Tehran, Iran. The inclusion criteria were being a female, presenting with abdominal pain, being a suspected case of acute appendicitis, and undergoing an emergency appendectomy. Patients younger than 13 years old, pregnant women and patients with uncompleted medical reports were excluded from the present study. Ethical approval for the study was obtained from the ethics committee of Shahid Beheshti University of Medical Sciences, Tehran, Iran.

Out of 477 reviewed medical records chosen based on inclusion and exclusion criteria, 433 medical records were complete and entered the study. Confirmation of appendicitis was based on histological analysis of the resected appendix at the Department of Histopathology, Imam Hossein Medical Center. Out of 477 patients entering the study, $295(68.12 \%)$ were positive for appendicitis based pathological results, and for the rest of patients, the pathological examination was not positive. The studied demographics, symptoms, clinical signs and laboratory- sonography investigation results collected in this study included age, presence of acute pain at admission, duration of pain, anorexia, nausea and vomiting, tenderness, presence of ovarian mass, leukocytosis, PMN count, hemoglobin level, body temperature.

\section{Devising a new predicting model for appendicitis}

A classification and regression tree (CART) model was used to partition exam and laboratory data obtained from patients into homogeneous groups in order to develop a prediction rule for appendicitis diagnosis. CART creates a tree-based classification. At each parent node of the tree, the CART algorithm selects the independent variable that has the highest association with the binary dependent variable according to specific criteria. Gini index was used as splitting criteria for each parent nodes. A 10-fold crossvalidation procedure was used to suggest the optimal number of leaves on the tree. The minimum number of observations in parent and child nodes was 20 and 10 , respectively.

\section{Statistical Analysis}

Quantitative data were presented as mean or median with inter quartile range, and qualitative data were shown as frequency and percent. Chi-square test, independent sample t-test, and Mann-Whitney test were used for bivariate analysis. All statistical analysis was performed using a 0.05 significance level. The area under the receiver operation characteristic (ROC) curve was calculated to evaluate the accuracy of the prediction model. Statistical package R 3.2.1 was used for all statistical analyses.

\section{Results}

The study population included 433 non pregnant women who underwent emergency operations with a preliminary diagnosis of acute appendicis. Out of these 295 patients (68.1\%) were appendicitis positive based on the pathology exam results, while 138 patients had a normal appendix, indicating a negative appendectomy rate of $31.8 \%$. The demographic data of patients entering the study is summarized in Table 1.

The mean age of the patients was $26.08 \pm 13.62$ with a range of 13-79 years. The mean was $26.76 \pm 13.75$ and $24.62 \pm 13.25$ in appendicitis positive and appendicitis negative groups, respectively $(\mathrm{p}=0.127)$ (Table 1$)$. A higher proportion of appendicitis positive patients was older than 25 years in comparison to the appendicitis negative patients $(51.5 \%$ versus $39.1 \%$; $=0.016)$ (Table 2$)$. A higher proportion of the appendicitis positive patients had $\mathrm{PMN}>$ $70 \%$ in comparison to the appendicitis negative patients $(78.3 \%$ versus $68.1 \%)(p=0.015)$ (Table 2$)$. The mean hemoglobin level among appendicitis positive and negative patients was $12.19 \pm 1.30$ and $12.61 \pm 1.37$, respectively. The proportion of patients with hemoglobin levels lower than 12 among positive appendicitis patients was significantly higher than appendicitis negative patients $(\mathrm{p}=0.030)$ (Table 2). Also, the mean temperature in appendicitis positive and negative cases were $37.15 \pm 0.63$ and $37.01 \pm 15^{\circ} \mathrm{C}$, respectively, indicating a statistically significant $(\mathrm{p}=0.042)$ difference, but this difference was at 
Table 1 . The demographic findings among patients entering the study

\begin{tabular}{|c|c|c|c|c|}
\hline Variable & $\begin{array}{c}\text { Total } \\
(\mathrm{N}=433) \\
\end{array}$ & $\begin{array}{c}\text { Appendicitis negative } \\
(\mathrm{N}=295)\end{array}$ & $\begin{array}{c}\text { Appendicitis positive } \\
(\mathrm{N}=138)\end{array}$ & $\mathrm{p}$ \\
\hline Drug usage N (\%) & $1(0.25)$ & $0(0)$ & $1(0.6 i)$ & 0.999 \\
\hline Using contraceptive $\mathrm{N}(\%)$ & $33(7.6)$ & $13(9.4)$ & $20(6.8)$ & 0.335 \\
\hline History of pain N (\%) & $17(3.9)$ & $6(4.3)$ & $11(3.7)$ & 0.757 \\
\hline Regularity of Menstruation N (\%) & $83(19.2)$ & $28(20.3)$ & $55(18.6)$ & 0.685 \\
\hline Discharge N $(\%)$ & $27(6.2)$ & $11(8)$ & $16(5.4)$ & 0.307 \\
\hline History of Discharge N (\%) & $13(11.4)$ & $2(6.9)$ & $11(12.9)$ & 0.510 \\
\hline Age $($ mean \pm SD $)$ & $26.08 \pm 13$ & $24.62 \pm 13.25$ & $26.76 \pm 13.75$ & 0.127 \\
\hline Variable & & $\begin{array}{l}\text { Appendicitis Positive } \\
(\mathrm{N}=295)\end{array}$ & $\begin{array}{l}\text { Appendicitis Negative } \\
(\mathrm{N}=138)\end{array}$ & $\mathrm{p}$ \\
\hline Anorexia $\mathrm{N}(\%)$ & & $260(88.13)$ & $119(86.23)$ & 0.578 \\
\hline Nausea and Vomiting N (\%) & & $252(85.42)$ & $117(84.78)$ & 0.861 \\
\hline Tenderness $\mathrm{N}(\%)$ & & $295(100)$ & $137(99.3)$ & 0.319 \\
\hline Rebound Tenderness N (\%) & & $241(81.7)$ & $113(81.8)$ & 0.962 \\
\hline Right Iliac Fossa Pain N (\%) & & $15(5.08)$ & $3(2.01)$ & 0.227 \\
\hline Ovarian Mass N (\%) & & $280(94)$ & $124(89.1)$ & 0.05 \\
\hline History Of Abdominal Incision N (\%) & & $65(22)$ & $31(22.5)$ & 0.920 \\
\hline \multicolumn{5}{|l|}{ Age Category N (\%) } \\
\hline$\leq 25$ & & $143(48.4)$ & $84(60.8)$ & 0.016 \\
\hline$>25$ & & $152(51.5)$ & $54(39.1)$ & \\
\hline Temperature (Centigrade) Mean \pm SD & & $37.15 \pm 0.63$ & $37.01 \pm 0.59$ & 0.042 \\
\hline Pain Duration Median (Iqr) & & $24(10-24)$ & $17.5(8-24)$ & 0.065 \\
\hline Leukocytosis Median (Iqr) & & $12(0-103)$ & $11(0-30)$ & 0.504 \\
\hline Pmn Median (Iqr) & & $80(1-97)$ & $76(6-95)$ & 0.005 \\
\hline Hemoglobin Mean \pm SD & & $12.19 \pm 1.30$ & $12.61 \pm 1.37$ & 0.002 \\
\hline
\end{tabular}

tenths of ${ }^{\circ} \mathrm{C}$ and was deemed as clinically insignificant. Ovarian mass was observed among $94 \%$ and $89.1 \%$ of appendicitis positive and negative patients, respectively $(\mathrm{p}=0.050)$. The two groups did not differ significantly regarding pain duration $(\mathrm{p}=0.065)$, anorexia $(\mathrm{p}=0.578)$, nausea and vomiting $(\mathrm{p}=0.861)$, right iliac fossa pain $(p=0.227)$, leukocytosis $(p=430)$, tenderness $(p=0.319)$, and rebound tenderness $(\mathrm{p}=0.962)$.

\section{Classification and regression tree (CART) analysis}

The age, PMN, hemoglobin, presence of acute pain, acute pain duration, history of incision, anorexia, nausea and vomiting and presence of ovarian mass were analyzed as parameters for a CART prediction model. The target variable was appendicitis pathology. The final tree is represented in Figure 1. The variables hemoglobin level, PMN count, age, and history of abdominal incision re-

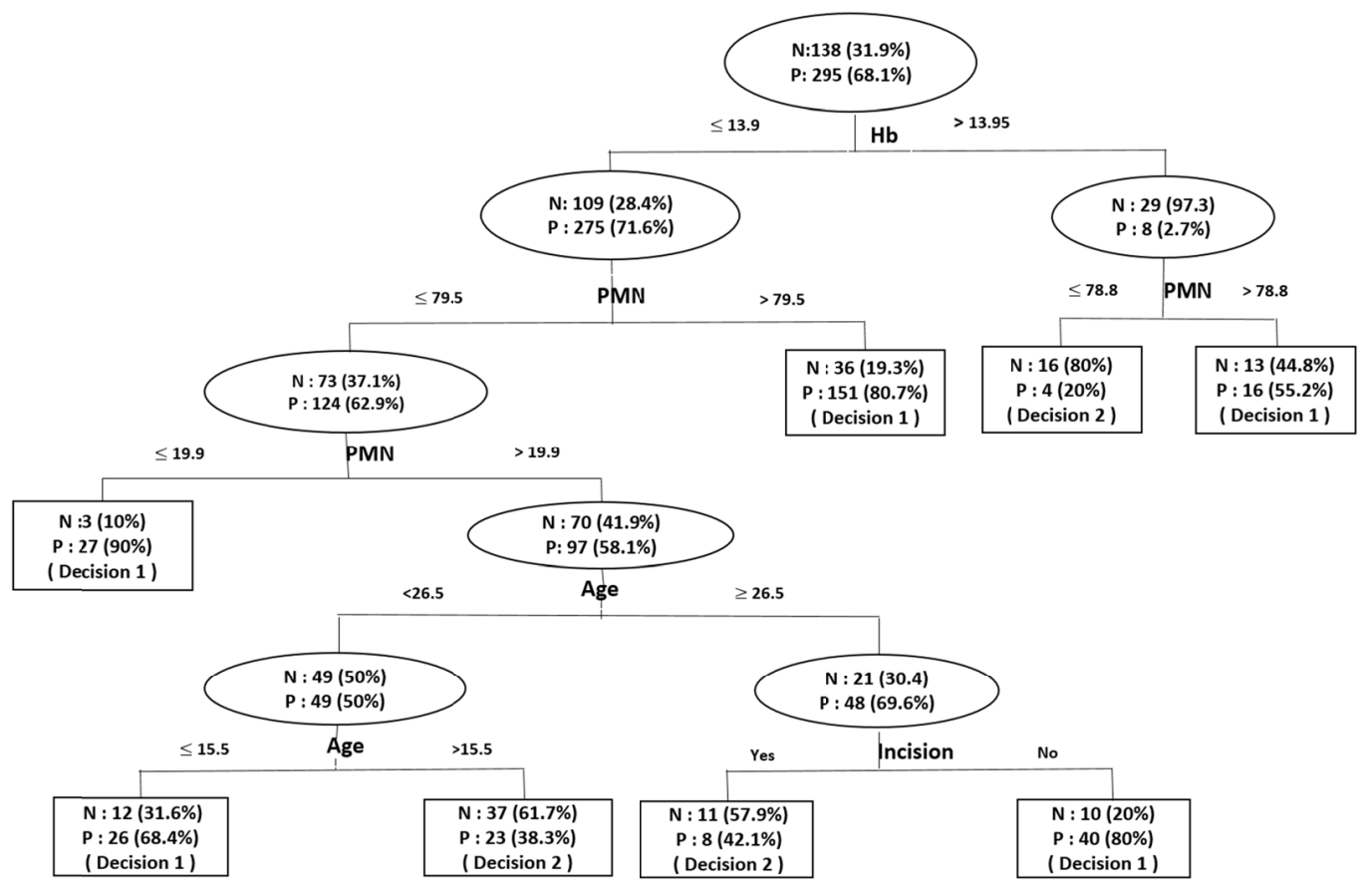

Fig. 1. CART model for appendicitis diagnosis

$\mathrm{N}$ : appendicitis negative; P: appendicitis positive; Decision 1: Operate; Decision 2: Observe 


\begin{tabular}{lcc} 
Table 3. Comparison of CART and Alvarado prediction models & \\
\hline Quantity & CART model & Alvarado score \\
\hline Sensitivity $(95 \%$ CI) & $82.71 \%(77.9 \%-86.8 \%)$ & $68.81 \%(63.2 \%-74.1 \%)$ \\
Specificity $(95 \%$ CI) & $55.8 \%(47.1 \%-64.2 \%)$ & $40.58 \%(32.3 \%-49.3 \%)$ \\
AUC $(95 \%$ CI) & $0.729(0.685-0.771)$ & $0.543(0.459-0.591)$ \\
\hline * P-value based on Delong test for comparison of AUCs. & $0.001 * *$ \\
\hline P &
\end{tabular}

** P-value based on McNemar's test.

AUC: Area under the (receiver operating characteristic) curve

mained in the CART model.

A comparison of sensitivity and specificity of CART and Alvarado prediction models is presented in Table 3. Our provided CART prediction model achieved sensitivity of $82.7 \%$ and specificity of $55.8 \%$.

\section{Discussion}

Acute abdominal pain is one of the most important causes of emergency surgical procedures among women and includes common causes such as ectopic pregnancy and complications of ovarian cyst, which often overlap with symptoms of appendicitis (5). Quick and accurate diagnosis and intervention are the main principals in minimizing the complications of acute appendicitis but they can be difficult at times $(1,2)$.

In the present study, we developed a CART model for decision making in the management of acute abdomen in non-pregnant women suspect of appendicis. In a retrospective study, this CART model achieved a sensitivity of $82.7 \%$ and specificity of $55.8 \%$, which was better than what Alvarado score (sensitivity 59\%, specificity 23\%) achieved in an Asian population according to Khan et al., (27). Also, Al-Hashemy et al., (28) reported a similarly lower sensitivity of (48\%) among female Middle Eastern patients, while in their study, the specificity was higher at $(62.5 \%)$. Wani et al., (29) have suggested that the sensitivity and specificity of the Alvarado scoring system vary with age and gender and the utility of Alvarado score in women and children remains controversial, while our target population was all women, and age was one of the main parameters in our model, which might reduce the detrimental effect of age and sex on our model. In the present study, the inclusion criteria were being a female, presenting with abdominal pain, being a suspected case of acute appendicitis, and undergoing an emergency appendectomy. Also, we excluded those patients younger than 13 years old, pregnant women and patients, with uncompleted medical reports. It is well documented that the rate of negative appendectomy in this group of patients is higher than the general population because of many different sources of abdominal pain other than appendicis in this group of patients compared to the general population which might explain the relatively high percentage of negative appendectomies in the present study. Radiological modalities such as CT scans have high sensitivity and specificity for diagnosing acute appendicitis, but the process of arrangement for imaging might cause a delay for emergency appendectomy (18). Also, the cost of health services and detection of early low-grade appendicitis which might resolve spontaneously without a need for appendectomy using imaging techniques, is considera- ble (18), while our model uses only 4 parameters, age, HB and PMN count and history of abdominal incisions, which are easily obtainable from a good clinical history and simple and cheep laboratory investigations.

Our new diagnosing model was specifically developed for non-pregnant women in our local patient population, but it is likely to be applicable to women in populations of similar ethnic origins and diets. This new model is a useful and rapid diagnostic tool that can be simply applied, as it requires only the patient's age, HB, and PMN counts and history of abdominal incision. The option of having simple parameters makes the model more flexible and adaptable to different geographical regions in terms of healthcare cost and may help to reduce unnecessary inpatient admissions or laparotomy.

This study was a retrospective analysis of patients' medical records, and hence, we missed cases with incomplete medical records. A prospective comparative evaluation of the models is recommended to fully evaluate the utilization of our new model.

\section{Conclusion}

We have devised a simple and cost effective prediction model for predicting the outcome among non-pregnant women undergoing emergency appendectomy operation with good sensitivity and specificity compared to the Alvarado model.

\section{Conflict of Interests}

The authors declare that they have no competing interests.

\section{References}

1. Humes DJ, Simpson J. Acute appendicitis. BMJ. 2006;333(7567):530-4.

2. Pal KM, Khan A. Appendicitis: a continuing challenge. J Pak Med Assoc. 1998;48(7):189-92.

3. Addiss DG, Shaffer N, Fowler BS, Tauxe RV. The epidemiology of appendicitis and appendectomy in the United States. Am J Epidemiol. 1990;132(5):910-25.

4. Körner H, Söndenaa K, Söreide JA, Andersen E, Nysted A, Lende $\mathrm{TH}$, et al. Incidence of acute nonperforated and perforated appendicitis: age-specific and sex-specific analysis. World J Surg. 1997:21(3):313-7.

5. Pages-Bouic E, Millet I, Curros-Doyon F, Faget C, Fontaine M, Taourel P. Acute pelvic pain in females in septic and aseptic contexts. Diagn Interv Imaging. 2015;96(10):985-95.

6. Gilmore OJ, Browett JP, Griffin PH, Ross IK, Brodribb AJ, Cooke $\mathrm{TJ}$, et al. Appendicitis and mimicking conditions. A prospective study. Lancet. 1975;2(7932):421-4.

7. Andersson RE. Meta-analysis of the clinical and laboratory diagnosis of appendicitis. Br J Surg. 2004;91(1):28-37.

8. Raja AS, Wright C, Sodickson AD, Zane RD, Schiff GD, Hanson R, Negative appendectomy rate in the era of CT: an 18-year perspective. Radiology. 2010;256(2):460-5.

9. Seetahal SA, Bolorunduro OB, Sookdeo TC, Oyetunji TA, Greene 
WR, Frederick W, et al. Negative appendectomy: a 10-year review of a nationally representative sample. Am J Surg. 2011;201(4):433-7.

10. Flum DR, Koepsell T. The clinical and economic correlates of misdiagnosed appendicitis: nationwide analysis. Arch Surg. 2002;137(7):799-804.

11. Blomqvist PG, Andersson RE, Granath F, Lambe MP, Ekbom AR. Mortality after appendectomy in Sweden, 1987-1996. Ann Surg. 2001;233(4):455-60.

12. Rao PM, Boland GW. Imaging of acute right lower abdominal quadrant pain. Clin Radiol. 1998;53(9):639-49.

13. Coursey CA, Nelson RC, Patel MB, Cochran C, Dodd LG, Delong $\mathrm{DM}$, et al. Making the diagnosis of acute appendicitis: do more preoperative CT scans mean fewer negative appendectomies? A 10year study. Radiology. 2010;254(2):460-8.

14. Wagner PL, Eachempati SR, Soe K, Pieracci FM, Shou J, Barie PS. Defining the current negative appendectomy rate: for whom is preoperative computed tomography making an impact? Surgery. 2008;144(2):276-82.

15. Lee SL, Walsh AJ, Ho HS. Computed tomography and ultrasonography do not improve and may delay the diagnosis and treatment of acute appendicitis. Arch Surg. 2001;136(5):556-62.

16. Hall EJ. Cancer risks from diagnostic radiology. $\mathrm{Br} \mathrm{J}$ Radiol. 2008;81(965):362-378

17. Alvarado A. A practical score for the early diagnosis of acute appendicitis. Ann Emerg Med. 1986;15(5):557-64.

18. Andersson M, Andersson RE. The appendicitis inflammatory response score: a tool for the diagnosis of acute appendicitis that outperforms the Alvarado score. World J Surg. 2008;32(8):1843-9.

19. Chong CF, Thien A, Mackie AJ, Tin AS, Tripathi S, Ahmad MA, et al. Comparison of RIPASA and Alvarado scores for the diagnosis of acute appendicitis. Singapore Med J. 2011;52(5):340-5.

20. Lintula H, Kokki H, Kettunen R, Eskelinen M. Appendicitis score for children with suspected appendicitis. A randomized clinical trial. Langenbecks Arch Surg. 2009;394(6):999-1004.

21. Lintula H, Kokki H, Pulkkinen J, Kettunen R, Gröhn O, Eskelinen M. Diagnostic score in acute appendicitis. Validation of a diagnostic score (Lintula score) for adults with suspected appendicitis. Langenbecks Arch Surg. 2010;395(5):495-500.

22. Samuel M. Pediatric appendicitis score. J Pediatr Surg. 2002;37(6):877-81

23. Kiely N, Williams N. Evaluation of the modified Alvarado score in the diagnosis of acute appendicitis: a prospective study. Ann R Coll Surg Engl. 1995;77(2):157.

24. Ohle R, O'Reilly F, O'Brien KK, Fahey T, Dimitrov BD. The Alvarado score for predicting acute appendicitis: a systematic review. BMC Med. 2011:9:139.

25. Kalan M, Talbot D, Cunliffe WJ, Rich AJ. Evaluation of the modified Alvarado score in the diagnosis of acute appendicitis: a prospective study. Ann R Coll Surg Engl. 1994;76(6):418-9.

26. Chong CF, Thien A, Mackie AJA, Suyoi A, Mackie AJ, Tin AS, et al. Evaluation of the RIPASA Score: a new appendicitis scoring system for the diagnosis of acute appendicitis. Brunei Int Med J. 2010;6:17-26.

27. Khan I, ur Rehman A. Application of Alvarado scoring system in diagnosis of acute appendicitis. J Ayub Med Coll Abbottabad. 2005;17(3):41-4.

28. Al-Hashemy AM, Seleem MI. Appraisal of the modified Alvarado Score for acute appendicits in adults. Saudi Med J. 2004;25:1229-31.

29. Wani MM, Yousaf MN, Khan MA, BabaAbdul A, Durrani M, Wani $\mathrm{M}$, et al. Usefulness of the Alvarado scoring system with respect to age, sex and time of presentation, with regression analysis of individual parameters. Internet J Surg [serial online]. 2007;11(2). 